\title{
Relationship between dietary carbohydrate quality index and metabolic syndrome among type 2 diabetes mellitus subjects: a case-control study from Ghana
}

\author{
Sufyan Bakuri Suara ${ }^{1}$, Fereydoun Siassi ${ }^{2^{*}}$, Mahama Saaka ${ }^{3}$, Abbas Rahimiforoushani ${ }^{4^{*}}$ and Gity Sotoudeh ${ }^{2^{*}}$
}

\begin{abstract}
Background: Dietary carbohydrate quality may play an important role in disease development. We evaluated the association between carbohydrate quality index (CQI) and the odds of metabolic syndrome (MetS) in type 2 diabetes mellitus (T2DM) subjects in Ghana.

Methods: In this case-control study, we analyzed data using 124 T2DM subjects. We obtained dietary information using 2-day 24-h dietary recalls. We calculated CQI from dietary fiber, glycemic index, whole grains/total grains ratio, and solid carbohydrates/total carbohydrates ratio. Serum lipid profiles were measured after an overnight fast of 8$12 \mathrm{~h}$.

Results: Upon adjustments for the effects of covariates, the CQI showed a positive association with high-density lipoprotein cholesterol concentration (beta coefficient $(\beta)=0.24$; standard error $(S E)=0.20$; $P$ for trend $=0.01$ ), and an inverse relationship with waist circumference $(\beta=-17.29 ; \mathrm{SE}=4.00 ; \mathrm{P}$ for trend $<0.001)$, systolic blood pressure $(\beta=-15.74 ; \mathrm{SE}=4.69 ; \mathrm{P}$ for trend $<0.001)$, diastolic blood pressure $(\beta=-7.23 ; \mathrm{SE}=2.97 ; \mathrm{P}$ for trend $=0.02)$, and triglyceride concentrations $(\beta=-0.43 ; \mathrm{SE}=0.11$; $P$ for trend $<0.001$ ). Overall, the CQI had an inverse relationship with the odds of MetS (Odds ratio tertile 3 vs.1 0.05; 95\% Confidence interval: 0.01-0.23; p-trend <0.001). Also, a positive correlation was found between the $\mathrm{CQI}$ and fiber, but the CQI showed a negative relationship with dietary glycemic index.

Conclusions: The present results suggest an inverse association between the CQI of a diet and the odds of MetS. The CQI approach of dietary recommendation may be a useful strategy for dietary carbohydrate selection for the prevention of MetS.
\end{abstract}

Keywords: Metabolic syndrome, Carbohydrate quality index, Obesity, Dyslipidemia, Overweight

\footnotetext{
* Correspondence: siassif@tums.ac.ir; rahimifo@tums.ac.ir;

gsotodeh@tums.ac.ir

2Department of Community Nutrition, School of Nutritional Sciences and

Dietetics, Tehran University of Medical Sciences, Hojatdost street, Naderi

street, Keshavarz Blv, Tehran, Iran

${ }^{4}$ Department of Epidemiology and Biostatistics, School of Public Health,

Tehran University of Medical Sciences, Tehran, Iran

Full list of author information is available at the end of the article
}

(c) The Author(s). 2021 Open Access This article is licensed under a Creative Commons Attribution 4.0 International License, which permits use, sharing, adaptation, distribution and reproduction in any medium or format, as long as you give appropriate credit to the original author(s) and the source, provide a link to the Creative Commons licence, and indicate if changes were made. The images or other third party material in this article are included in the article's Creative Commons licence, unless indicated otherwise in a credit line to the material. If material is not included in the article's Creative Commons licence and your intended use is not permitted by statutory regulation or exceeds the permitted use, you will need to obtain permission directly from the copyright holder. To view a copy of this licence, visit http://creativecommons.org/licenses/by/4.0/. The Creative Commons Public Domain Dedication waiver (http://creativecommons.org/publicdomain/zero/1.0/) applies to the data made available in this article, unless otherwise stated in a credit line to the data. 


\section{Background}

In most countries, about 20 to $30 \%$ of the general population could be suffering from metabolic syndrome (MetS) [1,2]. Among the Ghanaians with type 2 diabetes mellitus (T2DM), a high prevalence of MetS (24-78.8\%) has been reported using different diagnostic criteria [37]. The MetS is associated with higher rates of mortality [8], cardiovascular disease (CVD) and cancers [9], and infertility in both men [10] and women [11].

Diet and lifestyle interventions may be more effective in the prevention of MetS development than pharmacological agents [12-15]. Moreover, lifestyle modifications such as increased physical activity, adherence to a healthy diet, and weight loss are said to be associated with the reversion of MetS and its risk components [1622]. However, previous studies have mainly focused on investigating associations between limited indicators of dietary carbohydrate $(\mathrm{CHO})$ quality [glycemic index (GI), glycemic load (GL), fiber content, sugar-sweetened beverage intake and whole-grain food consumption] and the odds of MetS amongst T2DM subjects [23-32].

The above previous approaches [23-32] of evaluating dietary $\mathrm{CHO}$ quality are narrow and may not be representative of a holistic metabolic capacity of $\mathrm{CHO}$ diets. Therefore, a more comprehensive assessment of dietary $\mathrm{CHO}$ quality may be a better alternative in investigating relationships between the quality of dietary $\mathrm{CHO}$ consumed and the odds of MetS in T2DM subjects. In line with this, a previous study defined CQI by taking into account dietary fiber intake; GI; ratio of $\mathrm{CHO}$ consumed from whole grains to $\mathrm{CHO}$ consumed from total grains (WGTG), and ratio of $\mathrm{CHO}$ consumed from solid food items to total $\mathrm{CHO}$ consumed (RSCTC) [33]. Although the CQI brings together several dimensions of dietary $\mathrm{CHO}$ quality and may be an effective tool for nutrition counseling, very few studies have examined its relationship with metabolic outcomes [34-36]. Obesity is considered an important risk for the development of MetS [37]. In the recent past, we reported an inverse association between the CQI and general and abdominal obesity in Ghanaian healthy women [34]. However, this was a healthy population. Therefore, investigating the association between CQI and MetS in T2DM may provide useful data for the prevention of MetS.

Previous studies among the T2DM subjects in Africa only focused on assessing the level of physical activity [38], and the barriers to adequate nutrition in Ghana $[39,40]$. This perspective only provides limited insight into how to develop diet-related interventions that may be useful for the prevention of MetS, particularly amongst the T2DM subjects. Hence, a broader approach to the understanding of the quality of dietary $\mathrm{CHO}$ may be beneficial. Previously, Amugsi et al. [41] found that about $90 \%$ of the daily energy needs in the Ghanaian adult population come from dietary carbohydrates sources. The high intake of dietary $\mathrm{CHO}$ coupled with a high prevalence of MetS in the country could suggest that the intake of $\mathrm{CHO}$ may play a leading role in the health maintenance in the Ghanaian population than protein and fat intake. Hence, a broader evaluation of the quality of dietary $\mathrm{CHO}$ consumption amongst T2DM subjects may provide some information for the prevention of MetS and its risk components. Thus, the purpose of this study was to determine the association between dietary CQI and the odds of MetS among T2DM subjects in Tamale Metropolis, Ghana.

\section{Methods}

\section{Study design and population}

This case-control study was performed using registered T2DM patients who attend to diabetic clinics for their routine medical care within Tamale Metropolis. Recruitment of participants (Fig. 1) and data collection span the period of April to July 2019. The T2DM patients were assessed and 124 participants were recruited [62 of patients had MetS (case group) and 62 subjects were without the MetS (control group)]. Overall, 44, 42, and 38 patients were recruited from Tamale Teaching Hospital, Tamale Central Hospital, and Tamale West Hospital, respectively. The MetS was defined according to the International Diabetes Federation (IDF) [42]. In the definition, MetS can be diagnosed if waist circumference (WC): $\geq 94 \mathrm{~cm}$ (Male), $\geq 80 \mathrm{~cm}$ (Female) is accompanied by any two (2) of the following four (4) factors: raised triglycerides (TG) $[\geq 150 \mathrm{mg} / \mathrm{dl}(1.7 \mathrm{mmol} / \mathrm{L})$ or specific treatment for this lipid abnormality]; reduced high density lipoprotein cholesterol (HDL-c) $[<40 \mathrm{mg} / \mathrm{dl} \quad(1.03$ $\mathrm{mmol} / \mathrm{L})$ in males, or $<50 \mathrm{mg} / \mathrm{dl}(1.29 \mathrm{mmol} / \mathrm{L})$ in $\mathrm{fe}-$ males or specific treatment for this lipid abnormality]; raised blood pressure [systolic blood pressure $\geq 130$ or diastolic blood pressure $\geq 85 \mathrm{mmHg}$ or treatment of previously diagnosed hypertension]; Raised fasting plasma glucose $[(\mathrm{FPG}) \geq 100 \mathrm{mg} / \mathrm{dl}(5.6 \mathrm{mmol} / \mathrm{L})$, or previously diagnosed T2DM] [42].

To participate in the study, the subjects must have lived in the Tamale Metropolis, Ghana, for at least a year prior to the study. Moreover, the participants should have been living with T2DM for at least 1 year. However, we excluded potential subjects with known diseases (renal disease, thyroid disease, confirmed malaria, and human immune deficiency virus). Furthermore, pregnant and lactating women were excluded. Also, potential participants with severe nausea and vomiting were disqualified from participating in the study. We also excluded current smokers, insulin users and those placed on special diet therapies. Additionally, cases and controls were obtained based on frequency matching for the age (18-39, 40-49, and 50-59 years) and sex. 


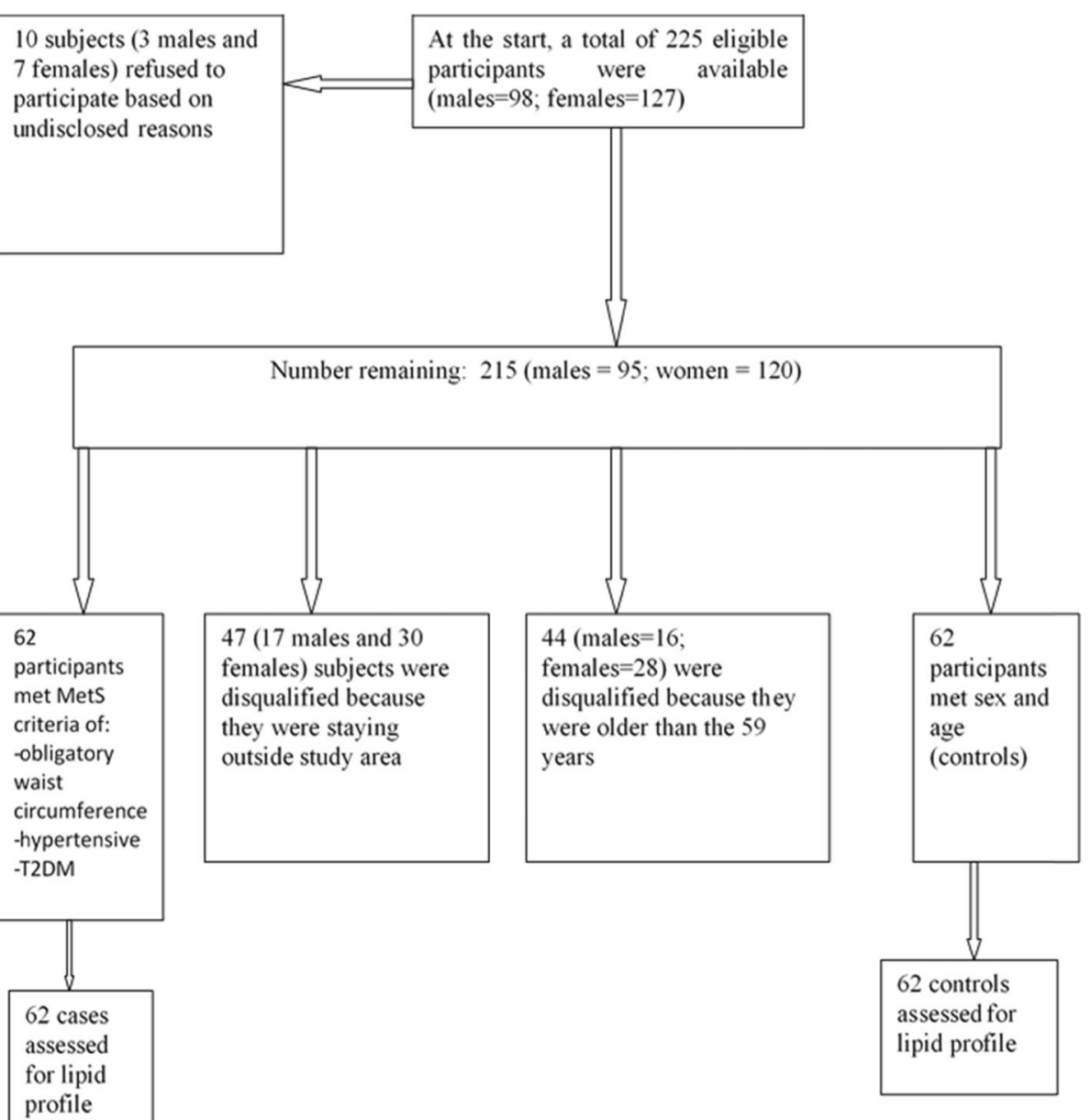

Fig. 1 Study subjects' sampling flow chart

The main objective of the study was to calculate the odds of MetS across a sex-specific energyadjusted CQI tertiles. So, based on a previous study [24], we adopted the odds of 3.19 for MetS between two quintiles of GI (Q3, Q1) with Q1 as a reference, to determine the number of subjects that we recruited into the case and the control groups. We used an online scientific protocol for the sample size calculation [43]. Based on the protocol, 62 cases and 62 controls were sampled.

\section{Biochemical parameters}

Serum TG, total cholesterol (TC), HDL-C, and lowdensity lipoprotein cholesterol (LDL-C) of diabetic patients were assayed to establish their metabolic profiles. The Tamale Teaching Hospital laboratory and Diabetic care clinics at Tamale Central Hospital and Tamale West Hospital were used as sentinel points for patient enrolment. Three milliliters of venous blood sample were taken from the antecubital vein of each subject using an aseptic technique.
The Venepuncture was done by an experienced phlebotomist and the samples immediately transferred into serum separator gel tubes which were then placed in a test tube rack. The specimen was collected in the morning after an overnight fast of 8 $12 \mathrm{~h}$. Following clot retraction, the serum separator tubes were centrifuged at $3000 \mathrm{rpm}$ for $10 \mathrm{~min}$ and the serum transferred into plain cryovials and frozen at $-20^{\circ} \mathrm{C}$ and stored for 6 six weeks before they were analyzed. All assays were done using the Vital Scientific's Flexor Junior Fully automated (with software version 4.1.x; manufacturer: Vital Scientific B. V, Netherlands, product ID: 6002-950-410-06) and Elitech reagents, calibrators, and controls manufactured by ElitechGroup, Puteaux, France. The assays were carried out at the Tamale Central Hospital Laboratory and in accordance with manufacturers' recommended protocols. Standard quality assurance procedures as per the ISO15189 and laboratories policies were observed during the pre-analytical, analytical and post-analytical stages. 


\section{Blood pressure (BP) measurement}

The blood pressure values of T2DM patients were measured after $10 \mathrm{~min}$ of rest while subjects were in a supine position using a digital arm sphygmomanometer [(OMRON HEALTHCARE Co. Ltd., Japan; model: OMRON M6 AC (HEM-7322-E); measurement range: pressure: 0 to $299 \mathrm{mmHg}$; pulse: 40 to 180 beats/min; accuracy: pressure: $\pm 3 \mathrm{mmHg}$; pulse: $\pm 5 \%$ of display reading. Cuff circumference 22 to $42 \mathrm{~cm}$ )]. The left arm was used and it was ensured that the upper arm was bare and un-constricted by clothing, without the legs crossed and arm resting firmly and supported on a table. Readings were recorded to the nearest $0.5 \mathrm{mmHg}$.

\section{Patient and public involvement}

This study included a sample of T2DM subjects. Although the participants were not involved in the study design process, their recruitment and participation were based on their own will.

\section{Dietary assessment and CQI calculation}

All dietary data were collected using repeated, nonconsecutive 2-day 24-h dietary recalls. We used real food items, food models, and kitchen weighing tools to guide study subjects in their estimation of food portion sizes consumed. A trained caterer was deployed to conduct face-to-face interviews following a 3-stage multiple-pass approach. This approach involves a quick listing of food items by respondents without any interruptions by the interviewer. This was followed by a detailed description and prompting for possibly forgotten food items. We obtained GI values from international tables [44]. Glucose was used as the reference (GI for glucose $=100$ ). We used the mean of the GI values in scenarios where more than one eligible GI values were available for a given foodstuff. GI values assessed using healthy subjects were prioritized in our selection of reference GI values. We obtained the GI for millet porridge from the University of Sydney GI database [45]. Also, the GI of sorghum [46], tuo-zaafi, and banku [47] were obtained from published articles. The carbohydrate content of dietary intake was determined using standard portion sizes from the United States Department of Agriculture (USDA) food composition databases [48]. In the analysis, the mean daily values of dietary energy, fiber, and total carbohydrates from the 2-day 24-h recalls were used. The weighted daily dietary GIs were calculated following a standard protocol [35]: Weighted GI $=\Sigma \mathrm{CHOi} \times \mathrm{GIi} /$ daily total food carbohydrate content; where $\mathrm{CHOi}$ is each food's carbohydrate content, GIi is each food's GI. The GL value was calculated for each participant by multiplying the carbohydrate content in grams obtained from the portion of food consumed by the corresponding GI of that food divided by 100 . To obtain the daily weighted GL, we summed up the individual GL values for each food [49]. By definition, liquid carbohydrates were calculated as the sum of the carbohydrates from all sugar-sweetened beverages and fruit juices consumed. Also, solid carbohydrates were considered to be the carbohydrate content of the rest of the carbohydratebased food items [36].

The CQI was computed based on the energy-adjusted amount of total carbohydrate intake values using the residual method [50]. The CQI was defined by summing up the following four criteria: the ratio of solid carbohydrates to total carbohydrates, dietary fiber intake (g/day), GI, and the ratio of whole grains to total grains (whole grains, refined grains, and their products). For each of these four criteria, subjects were classified into quintile (Qs) and received a value (ranging from 1 to 5) according to each Q. However, we reversed the scoring of GI Qs; thus, those in the Q5 received 1 point and those in the Q1 received 5 points. Subsequently, the CQI was computed by adding together all the values of the four criteria (ranging from 4 to 20). Finally, the CQI was ranked into tertiles (Ts), a modification of an earlier approach [33-36].

\section{Anthropometric assessment}

We measured the weight to the nearest $100 \mathrm{~g}$ using a Seca weighing scale (Seca GmbH and Co. KG; 22,089 Hamburg, Germany; Model: 8741321009; designed in Germany; made in China). The height measurements were carried out using the United Nations Children Emergency Fund height board. The height values were recorded to the nearest $0.1 \mathrm{~cm}$. Body mass index (BMI) was determined by dividing the weight (in kilograms) by the height (in meters squared) [51]. The WC was obtained according to the World Health Organization standards. The values were measured at the mid-point between the lower border of the rib cage and the iliac crest using a non-stretchable fiber-glass measuring tape [52]. The $\mathrm{WC}$ was recorded to the nearest $0.1 \mathrm{~cm}$.

\section{Assessment of demographic and lifestyle factors}

All the data about the demographic and lifestyle factors (age, educational status, marital status, occupation, household size, household assets, parity, and physical activity) were collected from face-to-face interviews using structured questionnaires. To enable us to estimate the wealth status of each respondent's household, we created a composite score for the list of household items enumerated. A higher score was a proxy for a higher wealth status [34]. The physical activity levels of the subjects were estimated using the International Physical Activity Questionnaire short form [53]. The questionnaire estimated the time and the number of days within the previous week each person spent on walking and on doing 
moderate-intensity and vigorous-intensity activities. The total physical activity in metabolic equivalent (MET) was calculated from the summation of the total walking, total moderate and total vigorous activities in MET-minutes/ week score units.

\section{Statistical analysis}

To ensure the compliance of data suitability with the chosen analytic techniques, the Kolmogorov-Smirnov test was used to evaluate the normality of the data. All study variables that failed the normality test were logtransformed before they were used in the regression models.

The general characteristics of subjects were presented according to MetS status as means \pm standard deviations (SDs) for all continuous variables which met the normality test. For these variables, the independent t-test was used to assess the statistical significance. Also, we calculated the medians and interquartile ranges for variables that failed the normality test. To assess the statistical significance of those variables, we used the Mann-Whitney test. Moreover, percentages and simple counts for categorical variables were computed using the chi-square test.

The sex-specific energy-adjusted dietary CQI was used to classify controls into tertiles (Ts). To assess the differences of characteristics of controls across the Ts of CQI, the one-way analysis of variance (ANOVA) was used for continuous variables that the met normality test. We also calculated medians and interquartile ranges for those that failed the normality test.

The beta $(\beta)$ coefficients and standard errors (SE) for linear regressions between sex-specific energy-adjusted CQI and individual components of the MetS were calculated. Additionally, the binary logistic regression was used to determine odds ratios (ORs) and 95\% confidence intervals (CIs) for MetS across the Ts of the sex-specific energy-adjusted CQI. In model 1 , we adjusted for age, sex and T2DM duration (years). In model 2, we further adjusted for energy, physical activity, BMI and educational status. These adjusted variables were variables that either showed a significant relationship with CQI or have the tendency to influence the relationship between CQI and MetS. All statistical analyses were done using IBM Statistical Package for Social Sciences (version 24; SPSS Inc.), and $p<0.05$ was considered statistically significant.

\section{Results}

Characteristics of the controls and cases are presented in Table 1. Total $\mathrm{CHO}$ intake was higher in the case group compared with the controls $(P<0.001)$. However, participants in the case group reported lower intake of total fiber $(P<0.001)$, WGTGR $(P=0.02)$, and CQI $(P<$
0.001) compared with participants in the control group. Overall, body weight, BMI, WC, systolic blood pressure, diastolic blood pressure, and TG were significantly higher $(P<0.001)$ amongst cases when compared with their control counterparts.

Correlations between the sex-specific energyadjusted CQI and fiber, RSCTC, WGTCR, and GI are presented in Table 2. After adjustment for age, sex and T2DM duration, education, BMI, energy and physical activity, a positive correlation was found between the sex-specific energy-adjusted CQI and fiber $(r=0.82 ; P<0.001)$, RSCTC $(r=0.14 ; P=0.1)$, and WGTCR $(r=0.78 ; P<0.001)$. However, a negative correlation was found between dietary GI and the CQI $(r=-0.61 ; P<0.001)$. Moreover, total fiber (25.3\%), and RSCTC (28.9\%) had a higher contribution to the overall CQI in females compared with males. However, in all subjects combined, total fiber (24.2\%), WGTGR (24.4\%), and GI (24.5\%) had a similar contribution to the CQI. Meanwhile, the RSCTC (26.8\%) showed the highest contribution to CQI (Table 3).

Characteristics of 62 controls across sex-specific energy-adjusted CQI tertiles are presented in Table 4. Total dietary fat intake had a positive association with CQI ( $\mathrm{P}$ for trend $=0.01$ ). The CQI showed a positive relationship with total fiber ( $\mathrm{P}$ for trend $<0.001$ ), RSCTC ( $\mathrm{P}$ for trend $<0.001$ ), and WGTGR ( $\mathrm{P}$ for trend $<0.001$ ). Conversely, a negative association was found between the CQI and GI ( $\mathrm{P}$ for trend $=0.001$ ), and GL ( $\mathrm{P}$ for trend $=0.04$ ).

The relationship between the sex-specific energyadjusted CQI and anthropometric variables, FBS, and serum lipid concentrations are presented in Table 5 . After an adjustment for the effects of age, sex and T2DM duration, the CQI was negatively associated with waist circumference (WC) $(\beta=-17.96 ; \mathrm{SE}=4.35$; $\mathrm{P}$ for trend $<0.001$ ), systolic blood pressure (SBP) $(\beta=16.09 ; \mathrm{SE}=4.74 ; \mathrm{P}$ for trend $<0.001)$, diastolic blood pressure (DBP) $(\beta=-7.62$; $\mathrm{SE}=2.97$; $\mathrm{P}$ for trend $=$ $0.007)$ and TG $(\beta=-0.45$; $\mathrm{SE}=0.12$; $\mathrm{P}$ for trend $<0.001)$. However, the CQI showed a positive association with HDL-C $(\beta=0.23$; SE $=0.20$; $\mathrm{P}$ for trend $=0.009)$. After additional adjustments for the effects of education, energy, physical activity, and BMI (except when it was used as a dependent variable), $\mathrm{WC}(\beta=-17.29$; $\mathrm{SE}=4.00 ; \mathrm{P}$ for trend $<0.001)$, SBP $(\beta=-15.74 ; \mathrm{SE}=4.69$; $\mathrm{P}$ for trend $<$ $0.001)$, DBP $(\beta=-7.23$; $\mathrm{SE}=2.97$; $\mathrm{P}$ for trend $=0.02)$ and TG $(\beta=-0.43$; SE $=0.11$; for trend $<0.001)$ still had a negative association with the CQI. Also, a significant positive relationship between the CQI and HDL-C ( $\beta=0.24$; $\mathrm{SE}=0.20$; $\mathrm{P}$ for trend $=0.01$ ) was still maintained. The CQI showed a positive association with the LDL-C/HDL-C ratio $(\beta=0.14 ; \mathrm{SE}=0.20$; $\mathrm{P}$ for trend $=0.04)$. 
Table 1 Characteristics of T2DM patients without (controls) and with (cases) MetS

\begin{tabular}{|c|c|c|c|}
\hline Variables & $\begin{array}{l}\text { Controls } \\
(n=62)\end{array}$ & $\begin{array}{l}\text { Cases } \\
(n=62)\end{array}$ & $P$-value \\
\hline$\overline{\text { Age (years }}$ & $45[17.3]$ & $47.5[21.0]$ & $0.9^{\mp}$ \\
\hline \multicolumn{4}{|l|}{ Sex, n (\%) } \\
\hline Male & $31(50.0)$ & $31(50.0)$ & \multirow[t]{2}{*}{$1.0^{*}$} \\
\hline female & $31(50.0)$ & $31(50.0)$ & \\
\hline \multicolumn{4}{|l|}{ Education } \\
\hline Non-tertiary & $42(46.2)$ & $49(53.8)$ & \multirow[t]{2}{*}{$0.2^{*}$} \\
\hline Tertiary & $20(60.6)$ & $13(39.4)$ & \\
\hline \multicolumn{4}{|l|}{ Occupation } \\
\hline Farming and trading & $42(45.2)$ & $51(54.8)$ & \multirow[t]{2}{*}{$0.1^{*}$} \\
\hline Salary worker & $20(64.5)$ & $11(35.5)$ & \\
\hline \multicolumn{4}{|l|}{ Marital Status } \\
\hline Single & $3(33.3)$ & $6(66.7)$ & \multirow[t]{2}{*}{$0.4^{*}$} \\
\hline Married & $59(51.3)$ & $56(48.7)$ & \\
\hline \multicolumn{4}{|l|}{${ }^{\pi}$ Medication use } \\
\hline No & $3(42.9)$ & $4(57.1)$ & \multirow[t]{2}{*}{$0.7^{*}$} \\
\hline Yes & $59(50.4)$ & $58(49.6)$ & \\
\hline Physical activity (MET-minutes/week) & $2260.5[4504.5]$ & $2646.0[5475.3]$ & $0.8^{\ddagger}$ \\
\hline${ }^{*}$ Asset score & $22.0[4.3]$ & $23.0[6.2]$ & $0.4^{\ddagger}$ \\
\hline Duration of T2DM (years) & $5.0[6.0]$ & $4.0[4.0]$ & $0.2^{\ddagger}$ \\
\hline Household size & $6.0[4.0]$ & $6.0[5.0]$ & $0.1^{\ddagger}$ \\
\hline Energy intake (kcal/d) & $1481.8 \pm 457.1$ & $1756.90 \pm 380.3$ & $<0.001^{* * *}$ \\
\hline Fat intake $(\mathrm{g} / \mathrm{d})$ & $14.1[6.2]$ & $13.2[8.4]$ & $0.4^{\ddagger}$ \\
\hline Protein intake (g/d) & $40.5[15.5]$ & $42.6[21.5]$ & $0.1^{\ddagger}$ \\
\hline $\mathrm{CHO}$ intake $(\mathrm{g} / \mathrm{d})$ & $291.50 \pm 103.4$ & $358.9 \pm 88.2$ & $<0.001^{* *}$ \\
\hline Fiber intake $(\mathrm{g} / \mathrm{d})$ & $20.5[8.5]$ & $13.6[5.2]$ & $<0.001^{\ddagger}$ \\
\hline RSCTC intake & $0.89[0.20]$ & $0.88[0.19]$ & $0.3^{\ddagger}$ \\
\hline WGTGR intake & $0.53[0.38]$ & $0.20[0.27]$ & $<0.001^{\ddagger}$ \\
\hline Energy adjusted glycemic index & $66.6[3.2]$ & $67.29[3.3]$ & $0.02^{\ddagger}$ \\
\hline Energy adjusted glycemic load & $212.9[22.2]$ & $220.2[28.8]$ & $0.050^{\ddagger}$ \\
\hline CQI & $15.0[4.0]$ & $10.0[4.0]$ & $<0.001^{\ddagger}$ \\
\hline Weight (Kg) & $69.8 \pm 13.1$ & $82.7 \pm 14.8$ & $<0.001^{* *}$ \\
\hline Height $(\mathrm{cm})$ & $162.5[13.5]$ & 161.1 [12.03] & $0.5^{\ddagger}$ \\
\hline Body mass index $\left(\mathrm{kgm}^{-2}\right)$ & $25.7[7.4]$ & $30.6[7.7]$ & $<0.001^{\ddagger}$ \\
\hline Waist circumference $(\mathrm{cm})$ & $81.8[15.05]$ & $114.0[18.8]$ & $<0.001^{\ddagger}$ \\
\hline Systolic blood Pressure (mmHg) & $121.5[6.0]$ & $137.0[23.5]$ & $<0.001^{\ddagger}$ \\
\hline Diastolic blood pressure $(\mathrm{mmHg})$ & $76.5[11.2]$ & $85.5[12.0]$ & $<0.001^{\ddagger}$ \\
\hline Triglycerides $(\mathrm{mmol} / \mathrm{l})$ & $1.50 \pm 0.39$ & $2.18 \pm 0.40$ & $<0.001^{* *}$ \\
\hline $\mathrm{HDL}-\mathrm{C}(\mathrm{mmol} / \mathrm{l})$ & $1.14[0.26]$ & $1.17[0.25]$ & $0.054^{\ddagger}$ \\
\hline LDL-C (mmol/l) & $3.33[1.37]$ & $3.31[0.87]$ & $0.7^{\ddagger}$ \\
\hline $\mathrm{TC}(\mathrm{mmol} / \mathrm{l})$ & $5.19[1.37]$ & $5.54[1.13]$ & $0.053^{\ddagger}$ \\
\hline$\Omega^{2}$ Fasting blood sugar ( $\left.\mathrm{mmol} / \mathrm{l}\right)$ & $8.4 \pm 2.5$ & $9.0 \pm 3.6$ & $0.2^{* *}$ \\
\hline LDL-C/HDL-C ratio & $3.15[1.12]$ & $2.72[1.37]$ & $0.8^{\ddagger}$ \\
\hline
\end{tabular}

Unadjusted and adjusted ORs and 95\% CIs for MetS across Ts of CQI are provided in Table 6. After an initial adjustment for the effects of age, sex and T2DM duration, the CQI had an inverse relationship with the odds of MetS

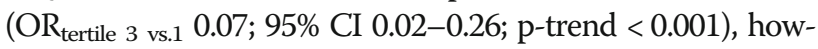
ever, this was a weak relationship though it attained a statistical significance. Moreover, after additional adjustment for
BMI, energy, physical activity, and education, there was still an inverse association between the CQI and the odds of MetS (OR tertile 3 vs.1 0.05; 95\% CI 0.01-0.23; p-trend < 0.001).

\section{Discussion}

The present study examined the relationship between a dietary sex-specific energy-adjusted CQI and the odds of 
Table 2 Correlation between sex-specific energy-adjusted CQI and total dietary fiber, RSCTC, WGTGR, and Gl ${ }^{\mathrm{a}}$

\begin{tabular}{lll}
\hline $\begin{array}{l}\text { CQI } \\
\text { component }\end{array}$ & Partial Correlation $(\boldsymbol{n}=\mathbf{1 2 4})$ & $\begin{array}{l}\boldsymbol{P} \\
\text { value }\end{array}$ \\
\hline Fiber & $\mathbf{r}$ & $<0.001$ \\
RSCTC & 0.82 & 0.1 \\
WGTGR & 0.14 & $<0.001$ \\
Gl & 0.78 & $<0.001$ \\
\hline
\end{tabular}

a Partial correlations between CQI and total dietary fiber, RSCTC, WGTGR, and Gl were adjusted for age, sex and duration of type 2 diabetes, education, BMl, energy and physical activity. CHO Carbohydrate, WGTGR ratio of $\mathrm{CHO}$ consumed from whole grains to $\mathrm{CHO}$ consumed from total grains, RSCTC ratio of $\mathrm{CHO}$ consumed from solid food items to total $\mathrm{CHO}$ consumed, $\mathrm{CQI}$ Carbohydrate quality index

MetS among T2DM subjects. There was an inverse association between the CQI and the odds of MetS. Also, a positive correlation was found between the CQI and fiber, RSCTC, and WGTCR but the CQI showed a negative relationship with GI. Moreover, the CQI had a positive association with high $\mathrm{HDL}-\mathrm{C}$, and an inverse relationship with WC, SBP, DBP, and TG.

Previous studies among T2DM subjects in SubSaharan Africa only focused on assessing lifestyle factors such as the level of physical activity in Nigeria [38], and in Ghana, barriers to adequate nutrition $[39,40]$ and associations between dietary diversity and BMI [54]. In the country, the majority of studies among T2DM subjects were focused on assessing the prevalence of MetS but did not investigate the possible dietary risk factors associated with MetS prevalence [3-7]. This perspective only provides limited insight into how to develop diet-related interventions for the prevention of metabolic disorders. Therefore, the present comprehensive evaluation of the quality of dietary carbohydrates consumed among Ghanaian T2DM subjects may help refine nutrition policy in the country, especially that about $90 \%$ of the daily energy need in the Ghanaian adult population comes from dietary carbohydrates [41].

In our study, the CQI was negatively associated with WC, SBP, DBP, TG, and the odds of MetS. However, the CQI showed a positive association with HDL-C. These associations as observed in the present study contravened previous results reported from a cross-sectional study in South Koreans, in which CQI failed to show a

Table 3 Contribution of fiber, RSCTC, WGTCR, and GI to sexspecific energy-adjusted CQI intake (\%)

\begin{tabular}{lllll}
\hline & Fiber & RSCTC & WGTGR & Gl \\
\hline Male & 23.2 & 24.7 & 25.7 & 26.5 \\
Female & 25.3 & 28.9 & 23.2 & 22.6 \\
Total & 24.2 & 26.8 & 24.4 & 24.5 \\
\hline
\end{tabular}

CHO Carbohydrate, WGTGR ratio of $\mathrm{CHO}$ consumed from whole grains to $\mathrm{CHO}$ consumed from total grains, RSCTC ratio of $\mathrm{CHO}$ consumed from solid food items to total $\mathrm{CHO}$ consumed, $\mathrm{CQ} / \mathrm{Carbohydrate}$ quality index relationship with MetS and its component factors the WC, HDL-C, TG, TC, and FBS [35]. Several factors may have contributed to the variations in the results of the two studies. For instance, we studied T2DM subjects in a case-control setting whereas, they analyzed data on a mixed population of adults with some far older than the age limit set for our study. Moreover, a repeated 24-h dietary recall was used in the present study whilst they used a single 24-h recall. Furthermore, we used the residual method to adjust for energy intake before the calculation of the sex-specific energy-adjusted CQI whereas, they used unadjusted dietary fiber, GI and carbohydrates in the CQI calculation.

Notwithstanding the variations in results between the present study and the Korean study [35], the two studies share some similarities. In line with the inverse association between the CQI and the odds of the measures of hypertension (SBP and DBP) found in the present study, the Korean study also reported an inverse association between CQI and prevalence of hypertension. Also, the inverse association between the CQI and the odds of high WC agrees with our previous results reported in Ghanaian healthy women, in which CQI showed a negative association with abdominal obesity indicated by WC. Diets high in CQI are healthy since a higher CQI is directly associated with fiber intake, whole grain product consumption, solid carbohydrate food consumption, and are low in GI. In numerous previous studies, these components of the CQI have shown favorable relationships with MetS and/or insulin sensitivity, high HDL-C, and low TG, LDL, SBP, DBP, and WC in T2DM subjects and the general population [22, 26-28, 30, 55-58].

Although the mechanisms that underlie the inverse association between the CQI and the MetS in the present study are unknown, previous mechanistic studies have espoused various explanations on how the components of the CQI may affect the occurrence of MetS and its risk factors. For example, dietary fiber is associated with lower postprandial glucose levels and increased insulin sensitivity in diabetics and healthy subjects [59-61], thereby preventing the insulin resistance component of the MetS. Also, the results from clinical trials [62-70] and meta-analyses [71, 72] support the cholesterolreducing effects and the prevention of hypertension and the improvements in the clinical features of MetS (glycemic control, lipoprotein profile, BMI, and blood pressure). Also, whole-grain consumption has the effect of prolonged satiety and also the capacity to slow down starch digestion and absorption and may as well lead to lower glucose and insulin responses [73, 74], and the prevention of obesity $[75,76]$, which are beneficial conditions for reducing the development of MetS. On the other hand, there are evidences from randomized controlled clinical trials and meta-analysis of randomized 
Table 4 Characteristics of 62 control group across tertiles of sex-specific energy-adjusted CQI

\begin{tabular}{|c|c|c|c|c|}
\hline \multirow{2}{*}{ Range } & \multirow[b]{2}{*}{ T1 (7.0-12.0) } & \multicolumn{2}{|l|}{ CQI Tertiles (Ts) } & \multirow[b]{2}{*}{$P$ for Trend } \\
\hline & & $\mathrm{T} 2(13.0-15.0)$ & T3 (16.0-20) & \\
\hline Number of participants & 22 & 22 & 18 & \\
\hline CQI, median (g/d) & 12.0 & 15.0 & 17.0 & \\
\hline Age (years), median [IQR] & $45.0[20.8]$ & $44.0[14.0]$ & $49.0[19.0]$ & 0.9 \\
\hline \multicolumn{5}{|l|}{ Sex } \\
\hline Male & $12(38.7)$ & $9(29.0)$ & $10(32.3)$ & \multirow[t]{2}{*}{0.4} \\
\hline Female & $10(32.3)$ & $13(41.9 \%)$ & $8(25.8)$ & \\
\hline \multicolumn{5}{|l|}{ Education } \\
\hline Non-tertiary & 13(31.0) & 14(33.3) & $15(35.7)$ & \multirow[t]{2}{*}{0.9} \\
\hline Tertiary & $9(45.0)$ & $8(40.0)$ & $3(15.0)$ & \\
\hline \multicolumn{5}{|l|}{ Occupation } \\
\hline Farming and trading & 14(33.3) & $12(28.6)$ & $16(38.1)$ & \multirow[t]{2}{*}{0.5} \\
\hline Salary worker & $8(40.0)$ & 10(50.0) & $2(10.0)$ & \\
\hline Duration of T2DM (years) & $5.0[6.0]$ & $4.5[3.5]$ & $4.5[8.0]$ & 0.3 \\
\hline Household size & $6.0[3.3]$ & $6.0[3.0]$ & $5.5[4.3]$ & 0.3 \\
\hline Asset score ${ }^{*}$ & $22.0[5.3]$ & $21.5[5.0]$ & $21.5[6.5]$ & 0.8 \\
\hline Physical activity (MET-minutes/week) & $2439.0[4377.7]$ & $2799.0[6255.0]$ & $2113.5[4404.3]$ & 0.8 \\
\hline Energy intake (kcal/d) & $1465.8 \pm 520.1$ & $1467.9 \pm 447.8$ & $1518.15 \pm 406.0$ & 0.2 \\
\hline Fat intake (g/d) & $12.3[5.2]$ & $14.7[6.5]$ & $16.96[6.07]$ & 0.01 \\
\hline Protein intake (g/d) & $38.4[12.1]$ & $38.4[19.1]$ & 46.06[20.03] & 0.7 \\
\hline $\mathrm{CHO}$ intake $(\mathrm{g} / \mathrm{d})$ & $291.3 \pm 123.5$ & $289.8 \pm 94.1$ & $293.7 \pm 92.5$ & 0.3 \\
\hline Fiber intake $(\mathrm{g} / \mathrm{d})$ & $17.0[5.4]$ & $21.3[6.5]$ & $26.86[8.80]$ & $<0.001$ \\
\hline RSCTC intake & $0.85[0.21]$ & $0.89[0.21]$ & $0.90[0.11]$ & $<0.001$ \\
\hline WGTGR intake & $0.27[0.31]$ & $0.55[0.37]$ & $0.77[0.34]$ & $<0.001$ \\
\hline Glycemic index & $67.3[2.0]$ & $66.6[2.5]$ & $64.5[2.7]$ & 0.001 \\
\hline Glycemic load & $220.9[19.7]$ & $212.0[17.3]$ & $201.08[26.5]$ & 0.04 \\
\hline Weight (Kg) & $70.8 \pm 14.8$ & $67.7 \pm 12.0$ & $71.1 \pm 12.4$ & 0.1 \\
\hline Height (cm) & $161.9[14.0]$ & $165.7[14.1]$ & $159.2[13.9]$ & 0.2 \\
\hline BMI $\left(\mathrm{kgm}^{-2}\right)$ & $25.1[8.2]$ & $24.7[7.5]$ & $28.2[4.9]$ & 0.7 \\
\hline Waist circumference (cm) & $89.8[18.3]$ & $78.3[14.3]$ & $85.1[15.5]$ & 0.2 \\
\hline Systolic blood Pressure mmHg & $123.5[4.5]$ & $120.0[7.7]$ & $122.0[7.8]$ & 0.9 \\
\hline Diastolic blood pressure (mmHg) & $76.0[13.2]$ & $77.0[6.7]$ & $72.5[12.8]$ & 0.7 \\
\hline Triglycerides (mmol/l) & $1.60 \pm 0.35$ & $1.39 \pm 0.43$ & $1.48 \pm 0.33$ & 0.2 \\
\hline $\mathrm{HDL}-\mathrm{C}(\mathrm{mmol} / \mathrm{l})$ & $1.16[0.29]$ & $1.07[0.29]$ & $1.14[0.23]$ & 0.8 \\
\hline LDL-C (mmol/l) & $3.20[1.31]$ & $3.51[1.55]$ & $3.12[1.56]$ & 0.2 \\
\hline Total cholesterol (mmol/l) & $5.17[1.22]$ & $5.27[1.65]$ & $4.97[3.76]$ & 0.3 \\
\hline$\Omega$ Fasting blood sugar (mmol/l) & $8.53 \pm 2.70$ & $8.70 \pm 2.44$ & $7.71 \pm 2.27$ & 0.5 \\
\hline LDL/HDL ratio & $2.83[1.22]$ & $3.38[1.14]$ & $3.07[1.04]$ & 0.4 \\
\hline
\end{tabular}

Data expressed as number (\%) or mean \pm standard deviation and median [interquartile range]; ${ }^{\Omega}$ Retrieved from patients ${ }^{\prime}$ folders. ${ }^{\ddagger}$ An ad hoc summary value was calculated from a list of household assets and room makeup. A score of 1 point was given for an item owned or room makeup includes local materials such as thatch or cow dung. As for the main source of cooking energy, drinking water and toilet facility, 1 point was given for unimproved source and 2 points awarded for improved sources. The total score range was from 37 to 74 with higher scores suggesting enhanced economic status. Kcal/d kilocalories per day, $g / d$ gram per day, $\mathrm{CHO}$ Carbohydrate, WGTGR ratio of $\mathrm{CHO}$ consumed from whole grains to $\mathrm{CHO}$ consumed from total grains, RSCTC ratio of CHO consumed from solid food items to total CHO consumed, CQI Carbohydrate quality index, HDL-C High density lipoprotein cholesterol, $L D L-C$ Low density lipoprotein cholesterol, P for trend test was performed using linear regression models where categorical covariates were entered as continuous variables using their dummies. Also, the CQI tertile classes were replaced by their respective medians 
Table 5 Linear regression analysis for cardiovascular risk factors across tertile (T) categories of sex-specific energy-adjusted CQI ${ }^{a}$ $(n=124)$

\begin{tabular}{|c|c|c|c|c|}
\hline & \multicolumn{3}{|c|}{ CQI } & \multirow[b]{2}{*}{$P$ for Trend } \\
\hline & $\mathrm{T} 1(7.0-12.0)$ & $\mathrm{T} 2(13.0-15.0)$ & T3 (16.0-20) & \\
\hline No. of cases/controls & $53 / 22$ & $6 / 22$ & $3 / 18$ & \\
\hline CQI, median (g/d) & 12.0 & 15.0 & 17.0 & \\
\hline \multicolumn{5}{|l|}{ Model 1} \\
\hline Body mass index $\left(\mathrm{kg} / \mathrm{m}^{2}\right)$ & Reference $^{b}$ & $-4.25(1.67)$ & $-1.06(1.87)$ & 0.1 \\
\hline Waist circumference (cm) & Reference & $-17.09(3.88)$ & $-17.96(4.35)$ & $<0.001$ \\
\hline Systolic blood pressure (mm Hg) & Reference & $-9.86(4.22)$ & $-16.09(4.74)$ & $<0.001$ \\
\hline Diastolic blood pressure (mm Hg) & Reference & $-4.22(2.65)$ & $-7.62(2.97)$ & 0.007 \\
\hline Blood glucose (mmol/l) & Reference & $0.02(0.68)$ & $-1.16(0.77)$ & 0.2 \\
\hline Total Cholesterol (mmol/l) & Reference & $-0.12(0.22)$ & $-0.13(0.24)$ & 0.5 \\
\hline Serum triglycerides $(\mathrm{mmol} / \mathrm{l})$ & Reference & $-0.41(0.11)$ & $-0.45(0.12)$ & $<0.001$ \\
\hline $\mathrm{HDL}-\mathrm{C}(\mathrm{mmol} / \mathrm{l})$ & Reference & $0.46(0.18)$ & $0.23(0.20)$ & 0.009 \\
\hline LDL-C (mmol/l) & Reference & $-0.14(0.04)$ & $-0.08(0.05)$ & 0.3 \\
\hline LDL-C/HDL-C & Reference & $0.21(0.18)$ & $0.14(0.20)$ & 0.050 \\
\hline \multicolumn{5}{|l|}{ Model 2} \\
\hline Body mass index $\left(\mathrm{kg} / \mathrm{m}^{2}\right)$ & Reference & $-3.75(1.55)$ & $-0.71(1.73)$ & 0.2 \\
\hline Waist circumference $(\mathrm{cm})$ & Reference & $-13.43(3.67)$ & $-17.29(4.00)$ & $<0.001$ \\
\hline Systolic blood pressure (mm Hg) & Reference & $-7.46(4.31)$ & $-15.74(4.69)$ & 0.001 \\
\hline Diastolic blood pressure (mm Hg) & Reference & $-3.03(2.73)$ & $-7.23(2.97)$ & 0.02 \\
\hline Blood glucose (mmol/l) & Reference & $0.01(0.72)$ & $-1.18(0.79)$ & 0.2 \\
\hline Serum triglycerides (mmol/l) & Reference & $-0.31(0.10)$ & $-0.43(0.11)$ & $<0.001$ \\
\hline $\mathrm{HDL}-\mathrm{C}(\mathrm{mmol} / \mathrm{l})$ & Reference & $0.55(0.19)$ & $0.24(0.20)$ & 0.01 \\
\hline LDL-C (mmol/l) & Reference & $-0.15(0.04)$ & $-0.07(0.05)$ & 0.2 \\
\hline LDL-C/HDL-C & Reference & $0.28(0.19)$ & $0.14(0.20)$ & 0.04 \\
\hline
\end{tabular}

${ }^{a}$ Data presented as $\beta$ (SE)

$\beta$ : unstandardized coefficient; SE: standard error (SE)

${ }^{\mathrm{b}} \mathrm{T} 1$ considered as reference and other tertiles compared with this tertile

CQI Carbohydrate quality index, HDL-C High density lipoprotein cholesterol, $L D L-C$ Low density lipoprotein cholesterol. CQI was categorized into tertiles according to the distribution of the control group. For overall subjects, the tertile classes for CQI were: T1 (4.0-6.0); T2 (7.0-8.0); T3 (9.0-12.0); OR Odds ratios, CI

Confidence interval

OR Odds ratio, $\mathrm{Cl}$ Confidence interval; Model 1: Adjusted for age, sex and duration of type 2 diabetes; Model 2: Further adjusted for education, energy, physical activity, and body mass index (except when it was used as a dependent variable). To test for a trend across the CQI, the median for each tertile of CQI was used as a continuous variable

Table 6 Odds ratios (ORs) and 95\% confidence intervals (Cls) MetS according to tertiles (Ts) of sex-specific energy-adjusted CQI indices

\begin{tabular}{|c|c|c|c|c|}
\hline CQI & $\mathrm{T} 1$ & $\mathrm{~T} 2$ & T3 & $P$ for Trend \\
\hline No. of cases/controls & $53 / 22$ & $6 / 22$ & $3 / 18$ & \\
\hline Median & 12.0 & 15.0 & 17.0 & \\
\hline Range & $(7.0-12.0)$ & $(13.0-15.0)$ & $(16.0-20)$ & \\
\hline \multicolumn{5}{|l|}{ OR $(95 \% \mathrm{Cl})$} \\
\hline Model 1 & 1.00 (Ref) & $0.11(0.04-0.32)$ & $0.07(0.02-0.26)$ & $<0.001$ \\
\hline$p$ & & $<0.001$ & $<0.001$ & \\
\hline Model 2 & 1.00 (Ref) & $0.13(0.04-0.42)$ & $0.05(0.01-0.23)$ & $<0.001$ \\
\hline$p$ & & 0.001 & $<0.001$ & \\
\hline
\end{tabular}

CQI, PSR, $\Sigma \boldsymbol{\omega}-\mathbf{3} / \Sigma \boldsymbol{\omega}-\mathbf{6}, \mathrm{h} / \mathrm{H}, \mathrm{Al}, \mathrm{Tl}$ and $\mathrm{LI}$ were categorized into tertiles according to the distribution of the control group For overall subjects, [CQI: T1(6.0-10.0); T2 (11.0-14.0); T3 (15.0-20.0)

$O R$ Odds ratios, $\mathrm{Cl}$ Confidence interval, CQI Carbohydrate quality index

Model 1: Adjusted for age, sex and duration of type 2 diabetes; Model 2: Further adjusted for BMl, energy, physical activity, education

To test for a trend across the sex-specific energy-adjusted CQI, the median for each tertile was used as a continuous variable 
controlled trials that in adults with MetS, low GI diets can cause significant decreases in anthropometric measurements, blood pressure, FBS and serum lipid profiles (TG, TC, LDL-C, HDL-C) [22, 55-58], which are beneficial for the prevention of MetS development. Moreover, liquid $\mathrm{CHO}$ diets such as the sugar-sweetened beverages are often high in GI [44, 77]; can increase postprandial blood glucose levels, decrease insulin sensitivity and increase the risk of obesity and overweight [77], which are also important risk factors for the MetS occurrence.

The present study has a number of important strengths. As far as we are aware, this study was the first to investigate CQI taking into account the sex-specific difference in carbohydrate consumption and its relationship with the MetS in Africa. Moreover, necessary precautions were taken to enhance data quality and study results during both data collection and analysis. However, the study was not without some inadequacies. First, the sample size was very small which may have lacked the necessary statistical power to reveal very important relations between the CQI and the MetS and/or its components. Second, this was an observational study, the findings did not establish a causal relationship between CQI and MetS. Third, we used 24-h dietary recall for dietary intake assessment therefore, there was the chance that some participants may have misreported their dietary intake due to memory-related issues. Additionally, there was the likelihood of underreporting of foods perceived to be undesirable for health and the chance for overreporting for food items perceived to be healthy. Although we controlled for some potential confounders, we cannot discount the effects of seasonal variations in food intake, genetic impact, and residual confounding. With these potential errors, the results ought to be interpreted with caution.

\section{Conclusions}

The present study found an inverse association between the CQI and the odds for MetS and reductions in WC, SBP, DBP, and TG but an in increase in HDL-C. This finding provides a piece of useful information which may guide carbohydrate nutrition planning for MetS prevention, particularly among T2DM subjects. However, experimental studies are needed to establish a possible causal relationship between the odds for MetS and dietary CQI intake.

\footnotetext{
Abbreviations

CQI: Carbohydrate quality index; GI: Glycemic Index (Gl); GL: Glycemic load; CHO: Carbohydrates; WGTGR: Ratio of $\mathrm{CHO}$ consumed from whole grains to $\mathrm{CHO}$ consumed from total grains; RSCTC: Ratio of $\mathrm{CHO}$ consumed from solid carbohydrate food items to total $\mathrm{CHO}$ consumed; BMI: Body mass index; WC: Circumference; IDF: International Diabetes Federation; UNICEF: United Nations Children Emergency Fund; WHO: World Health Organization; MetS: Metabolic syndrome; T2DM: Type 2 diabetes mellitus; FBS: Fasting blood sugar; TG: Triglycerides; TC: Total cholesterol; LDL-C: Low-density lipoprotein cholesterol; HDL-C: High-density lipoprotein cholesterol: BP: Blood pressure; MET: Metabolic equivalent; SDs: Means \pm standard
}

deviations; ANOVA: One-way analysis of variance; $\mathrm{Cl}$ : Confidence intervals; B: Unstandardized beta coefficient; SE: Standard error of beta; OR: Odds ratio; P: Statistical significance; Q: Quintile; T: Tertile

\section{Acknowledgments}

We are thankful to all participants of the study and the staff of International Campus of Tehran University of Medical Sciences.

\section{Authors' contributions}

SBS contributed substantially to the conception, design, and drafting of the manuscript. GS has made substantial contributions to the design, revised the manuscript critically and given final approval of the version to be submitted. MS has made substantial contributions to conception and revised the manuscript. FS has made substantial contribution to conception and design. ARF has contributed greatly in offering advice on statistical design and analysis. The author(s) read and approved the final manuscript.

\section{Funding}

This project was supported by the International Campus of Tehran University of Medical Sciences under grant number 9513475002.

\section{Availability of data and materials}

The datasets used to support the findings of the study are available from the corresponding author upon request.

\section{Declarations}

\section{Ethics approval and consent to participate}

The study was carried out in line with the Declaration of Helsinki. All study participants provided written informed consent. The study was approved by two ethics committees [(first, the Ethics Committee of Tehran University of Medical Sciences, Tehran, Iran (IR.TUMS.VCR.REC.1397.4928); second, the Ethics Review Committee of Tamale Teaching Hospital, Tamale, Ghana (TTHERC.19/06/18/02)].

\section{Consent for publication}

Not applicable.

\section{Competing interests}

None.

\section{Author details}

'Department of Community Nutrition, School of Nutritional Sciences and Dietetics, International Campus, Tehran University of Medical Sciences, Number 21 Dameshgh St. Vali-e Asr Ave., Tehran 1416753955, Iran.

${ }^{2}$ Department of Community Nutrition, School of Nutritional Sciences and Dietetics, Tehran University of Medical Sciences, Hojatdost street, Naderi street, Keshavarz Blv, Tehran, Iran. ${ }^{3}$ Department of Nutritional Sciences, School of Allied Health Sciences, University for Development Studies, Post Office Box 1350, Tamale, Ghana. ${ }^{4}$ Department of Epidemiology and Biostatistics, School of Public Health, Tehran University of Medical Sciences, Tehran, Iran.

Received: 28 November 2020 Accepted: 8 March 2021

Published online: 17 March 2021

\section{References}

1. van Vliet-Ostaptchouk JV, Nuotio M-L, Slagter SN, Doiron D, Fischer K, Foco $L$, et al. The prevalence of metabolic syndrome and metabolically healthy obesity in Europe: a collaborative analysis of ten large cohort studies. BMC Endocr Disord. 2014;14(1):9. https://doi.org/10.1186/1472-6823-14-9.

2. Xi B, He D, Hu Y, Zhou D. Prevalence of metabolic syndrome and its influencing factors among the Chinese adults: the China health and nutrition survey in 2009. Prev Med (Baltim). 2013;57(6):867-71. https://doi. org/10.1016/j.ypmed.2013.09.023

3. Osei-Yeboah J, Owiredu WKBA, Norgbe GK, Lokpo SY, Gyamfi J, Allotey EA, et al. The prevalence of metabolic syndrome and its components among people with type 2 diabetes in the Ho Municipality, Ghana: a cross-sectional study. Int J od Chronic Dis. 2017;2017:1-8.

4. Nsiah K, Vo S, Ka B, Mensah F. Prevalence of metabolic syndrome in type 2 diabetes mellitus patients. Int J Appl Basic Med Res. 2015:5:133. https://doi. org/10.4103/2229-516X.157170. 
5. Titty F. Glycaemic control, Dyslipidaemia and metabolic syndrome among recently diagnosed diabetes mellitus patients in tamale teaching hospital, Ghana. West Afr J Med. 2010;29.

6. Mogre V, Salifu ZS, Abedandi R. Prevalence, components and associated demographic and lifestyle factors of the metabolic syndrome in type 2 diabetes mellitus. J Diabetes Metab Disord. 2014;13(1). https://doi.org/10.1186/22516581-13-80.

7. Amidu N, Owiredu WK, Alidu H, Sarpong C, Gyasi-Sarpong CK, Quaye L. Association between metabolic syndrome and sexual dysfunction among men with clinically diagnosed diabetes. Diabetol Metab Syndr. 2013;5(1). https://doi.org/10.1186/1758-5996-5-42.

8. Mottillo S, Filion KB, Genest J, Joseph L, Pilote L, Poirier P, Rinfret S, Schiffrin EL, Eisenberg MJ. The metabolic syndrome and cardiovascular risk: a systematic review and meta-analysis. J Am Coll Cardiol. 2010;56(14):1113-32. https://doi.org/10.1016/j.jacc.2010.05.034.

9. O'Neill S, O'Driscoll L. Metabolic syndrome: a closer look at the growing epidemic and its associated pathologies. Obes Rev. 2015;16(1):1-12. https:// doi.org/10.1111/obr.12229.

10. Dupont C, Faure C, Daoud F, Gautier B, Czernichow S, Lévy R. Metabolic syndrome and smoking are independent risk factors of male idiopathic infertility. Basic Clin Androl. 2019;29(1):9. https://doi.org/10.1186/s12610-019-0090-x.

11. Al AA, Alkhayat $K$, Hammadeh ME. Metabolic Syndrome and Infertility in Women. Int J Women's Heal Reprod Sci. 2016;4:89-95. https:/doi.org/10.15296/ijwhr.2016.23.

12. Trial R, Orchard TJ, Temprosa M, Goldberg R, Haffner S, Ratner R. Article the effect of metformin and intensive lifestyle intervention on the metabolic syndrome : the diabetes prevention program. Ann Intern Med. 2005;142: 611-9 http://www.pubmedcentral.nih.gov/articlerender.fcgi?artid=250504 6\&tool=pmcentrez\&rendertype=abstract.

13. Mensink M, Blaak EE, Corpeleijn E, Saris WH, De Bruin TW, Feskens EJ. Lifestyle intervention according to general recommendations improves glucose tolerance. Obes Res. 2003;11(12):1588-96. https://doi.org/10.1038/oby.2003.211.

14. Knowler WC, Barrett-Connor E, Fowler SE, Hamman RF, Lachin JM, Walker EA, Nathan DM, Diabetes Prevention Program Research Group. Reduction in the incidence of type 2 diabetes with lifestyle intervention or metformin. N Engl J Med. 2002;346(6):393-403. https://doi.org/10.1056/NEJMoa012512.

15. Yamaoka $K$, Tango T. Effects of lifestyle modification on metabolic syndrome: a systematic review and meta-analysis. BMC Med. 2012;10(1). https://doi.org/10.1186/1741-7015-10-138.

16. Earnest CP, Johannsen NM, Swift DL, Lavie CJ, Blair SN, Church TS. Dose effect of cardiorespiratory exercise on metabolic syndrome in postmenopausal women. Am J Cardiol. 2013;111(12):1805-11. https://doi. org/10.1016/j.amjcard.2013.02.037.

17. Azadbakht L, Mirmiran P, Esmaillzadeh A, Azizi T, Azizi F. Beneficial effects of a dietary approaches to stop hypertension eating plan on features of the metabolic syndrome. Diabetes Care. 2005;28(12):2823-31. https://doi.org/1 0.2337/diacare.28.12.2823.

18. Akbaraly TN, Singh-Manoux A, Tabak AG, Jokela M, Virtanen M, Ferrie JE, Marmot MG, Shipley MJ, Kivimaki M. Overall diet history and reversibility of the metabolic syndrome over 5 years: the Whitehall II prospective cohort study. Diabetes Care. 2010;33(11):2339-41. https://doi.org/10.2337/dc09-2200.

19. Case CCC, Jones PHH. Nelson K, E OS, Ballantyne CMM. Impact of weight loss on the metabolic syndrome. Diabetes Obes Metab. 2002;4(6):407-14. http://www.ncbi.nlm.nih.gov/pubmed/12406040. https://doi.org/10.1046/j.14 63-1326.2002.00236.x.

20. Lofgren $\mathrm{IE}$, Herron $\mathrm{KL}$, West $\mathrm{KL}$, Zern $\mathrm{TL}$, Koo SI, Fernandez ML, et al. Weight loss favorably modifies anthropometrics and reverses the metabolic syndrome in premenopausal women. J Am Coll Nutr. 2005;24(6):486-93. https://doi.org/10.1080/07315724.2005.10719494.

21. De La Iglesia R, Lopez-Legarrea P, Abete I, Bondia-Pons I, Navas-Carretero S, Forga $L$, et al. A new dietary strategy for long-term treatment of the metabolic syndrome is compared with the American heart association (AHA) guidelines: the MEtabolic syndrome REduction in NAvarra (RESMENA) project. Br J Nutr. 2014;111(4):643-52. https://doi.org/10.1017/S0007114513002778.

22. Rajabi S, Mazloom Z, Zamani A, Tabatabaee HR. Effect of low glycemic index diet versus metformin on metabolic syndrome. Int J Endocrinol Metab. 2015;13(4):e23091. https://doi.org/10.5812/ijem.23091.

23. Lin X, Chen C, Lin D, Xu M, Yuan Z, He F, et al. Dietary glycemic load and metabolic status in newly diagnosed type 2 diabetes in southeastern China. Asia Pac J Clin Nutr. 2018;27(2):375-82. https://doi.org/10.6133/apjcn.052017.03.

24. Kim K, Yun SH, Choi BY, Kim MK. Cross-sectional relationship between dietary carbohydrate, glycaemic index, glycaemic load and risk of the metabolic syndrome in a Korean population. Br J Nutr. 2008;100(03):576-84. https://doi.org/10.1017/S0007114508904372

25. Farvid MS, Homayouni F, Shokoohi M, Fallah A, Farvid MS. Glycemic index, glycemic load and their association with glycemic control among patients with type 2 diabetes. Eur J Clin Nutr. 2014;68(4):459-63. https://doi.org/10.1 038/ejcn.2013.288.

26. Silva FM, Steemburgo T, de Mello VD, Tonding SF, Gross JL, Azevedo MJ. High dietary glycemic index and low fiber content are associated with metabolic syndrome in patients with type 2 diabetes. J Am Coll Nutr. 2011; 30(2):141-8. https://doi.org/10.1080/07315724.2011.10719953.

27. Menegotto G, Moraes Silva F, de Azevedo MJ, de Almeida JC. Lunch energy density and the metabolic syndrome in patients with type 2 diabetes mellitus. Br J Nutr. 2013;110(9):1656-63. https://doi.org/10.1017/S0007114513000846.

28. Steemburgo T, Dall'Alba V, Almeida JC, Zelmanovitz T, Gross JL, de Azevedo MJ. Intake of soluble fibers has a protective role for the presence of metabolic syndrome in patients with type 2 diabetes. Eur J Clin Nutr. 2009; 63(1):127-33. https://doi.org/10.1038/sj.ejcn.1602902.

29. Malik VS, Popkin BM, Bray GA, Despres JP, Willett WC, Hu FB. Sugar-sweetened beverages and risk of metabolic syndrome and type 2 diabetes: a metaanalysis. Diabetes Care. 2010;33(11):2477-81. https://doi.org/10.2337/dc10-1079.

30. Fujii H, Iwase M, Ohkuma T, Ogata-Kaizu S, Ide H, Kikuchi Y, Idewaki Y, Joudai T, Hirakawa Y, Uchida K, Sasaki S, Nakamura U, Kitazono T. Impact of dietary fiber intake on glycemic control, cardiovascular risk factors and chronic kidney disease in Japanese patients with type 2 diabetes mellitus: the Fukuoka diabetes registry. Nutr J. 2013;12(1). https://doi.org/10.1186/1475-2891-12-159.

31. Juanola-Falgarona M, Salas-Salvadõ J, Buil-Cosiales P, Corella D, Estruch R, Ros E, et al. Dietary glycemic index and glycemic load are positively associated with risk of developing metabolic syndrome in middle-aged and elderly adults. J Am Geriatr Soc. 2015;63(10):1991-2000. https://doi.org/10.1111/jgs.13668.

32. Hollænder PLB, Ross AB, Kristensen M. Whole-grain and blood lipid changes in apparently healthy adults: a systematic review and meta-analysis of randomized controlled studies. Am J Clin Nutr. 2015;102(3):556-72. https:// doi.org/10.3945/ajen.115.109165.

33. Zazpe I, Sánchez-Taínta A, Santiago S, de la Fuente-Arrillaga C, Bes-Rastrollo M, Martínez JA, Martínez-González MÁ. Association between dietary carbohydrate intake quality and micronutrient intake adequacy in a Mediterranean cohort: the SUN (Seguimiento Universidad de Navarra) project. Br J Nutr. 2014;111(11): 2000-9. https://doi.org/10.1017/S0007114513004364.

34. Suara SB, Siassi F, Saaka M, Rahimi Foroshani A, Sotoudeh G. Association between carbohydrate quality index and general and abdominal obesity in women: a cross-sectional study from Ghana. BMJ Open. 2019;9(12):e033038. https://doi.org/10.1136/bmjopen-2019-033038.

35. Kim D-Y, Kim SH, Lim H. Association between dietary carbohydrate quality and the prevalence of obesity and hypertension. J Hum Nutr Diet. 2018; 31(5):587-96. https://doi.org/10.1111/jhn.12559.

36. Santiago S, Zazpe I, Bes-Rastrollo M, Sánchez-Tainta A, Sayón-Orea C, De La Fuente-Arrillaga $C$, et al. Carbohydrate quality, weight change and incident obesity in a Mediterranean cohort: the SUN project. Eur J Clin Nutr. 2015; 69(3):297-302. https://doi.org/10.1038/ejcn.2014.187.

37. Alberti KGMM, Eckel RH, Grundy SM, Zimmet PZ, Cleeman Jl, Donato KA, Fruchart JC, James WP, Loria CM, Smith SC Jr, International Diabetes Federation Task Force on Epidemiology and Prevention, Hational Heart, Lung, and Blood Institute, American Heart Association, World Heart Federation, International Atherosclerosis Society, International Association for the Study of Obesity. Harmonizing the metabolic syndrome. Circulation. 2009;120(16):1640-5. https://doi.org/10.1161/CIRCULATIONAHA.109.192644.

38. Adeniyi AF, Fasanmade AA, Aiyegbusi OS, Uloko AE. Physical activity levels of type 2 diabetes patients seen at the outpatient diabetes clinics of two tertiary health institutions in Nigeria. Nig Q J Hosp Med. 2010;20(4):165-70. http://www.ncbi.nlm.nih.gov/pubmed/21913522.

39. Doherty ML, Owusu-Dabo E, Kantanka OS, Brawer RO, Plumb JD. Type 2 diabetes in a rapidly urbanizing region of Ghana. West Africa: a qualitative study of dietary preferences, knowledge and practices. BMC Public Health; 2014.

40. Mogre V, Johnson NA, Tzelepis F, Paul C. Barriers to diabetic self-care: a qualitative study of patients' and healthcare providers' perspectives. J Clin Nurs. 2019;28(11-12):2296-308. https://doi.org/10.1111/jocn.14835.

41. Amugsi DA, Mittelmark MB, Oduro A. Association between maternal and child dietary diversity: an analysis of the Ghana demographic and health survey. PLoS One. 2015;10:1-12.

42. Kassi E, Pervanidou P, Kaltsas G, Chrousos G. Metabolic syndrome: definitions and controversies. BMC Med. 2011;9(1):48. https://doi.org/10.1186/1741-7015-9-48. 
43. Designing clinical research : an epidemiologic approach. http://www.sa mple-size.net/sample-size-proportions.

44. Atkinson, Fiona SR, Foser-Powell K, Kaye R, Brand- Miller, Jennie CP. International Tables of Glycemic Index and Glycemic Load Values : 2008. Diabetes Care. 2008;31:2281-3.

45. Sydney U of. University of Sydney. Glycemic Index Research Service (SUGiRS - Gl Foods Advanced Search (web page). 2018. http://www.glycemicindex. com/foodSearch.php). Accessed 17 Oct 2018.

46. Prasad MPR, Rao BD, Kalpana K, Rao MV, Patil JV. Glycaemic index and glycaemic load of sorghum products. J Sci Food Agric. 2015;95(8):1626-30. https://doi.org/10.1002/jsfa.6861.

47. Eli-Cophie D, Agbenorhevi JK, Annan RA. Glycemic index of some local staples in Ghana. Food Sci Nutr. 2017;5(1):131-8. https://doi.org/10.1002/fsn3.372.

48. USDA. United States Department of Agriculture Food Composition Databases Show Nutrients List. 2018. https://ndb.nal.usda.gov/ndb/ nutrients/index.

49. Culberson A, Kafai MR, Ganji V. Glycemic load is associated with HDL cholesterol but not with the other components and prevalence of metabolic syndrome in the third national health and nutrition examination survey, 1988-1994. Int Arch Med. 2009;2:1-8.

50. Willett WSM. Total energy intake: implications for epidemiologic analyses. Am J Epidemiol. 1986;124(1):17-27. https://doi.org/10.1093/oxfordjournals.a je.a114366.

51. World Health Organization. Obesity: preventing and managing the global epidemic. Report of a WHO consultation. World Health Organ Tech Rep Ser. 2000;894:i-xii, 1-253. http://www.ncbi.n/m.nih.gov/pubmed/11234459.

52. WHO WHO. Waist circumference and waist-hip ratio: report of a WHO expert consultation Geneva, 8-11 December 2008; 2008.

53. International Physical Activity Questionniare Group. International physical activity questionnaire short last 7 days self-administered format for use with young and middle aged adults. Res Q Exerc Sport. 2002.

54. Christina AN, David A, Clara OO. Relationship between dietary practices, physical activity and body mass indices of type 2 diabetics attending a clinic in Accra, Ghana. J Public Heal Epidemiol. 2016;8(4):60-6. https://doi. org/10.5897/JPHE2015.0784.

55. Goff LM, Cowland DE, Hooper L, Frost GS. Low glycaemic index diets and blood lipids: a systematic review and meta-analysis of randomised controlled trials. Nutr Metab Cardiovasc Dis. 2013;23(1):1-10. https://doi. org/10.1016/j.numecd.2012.06.002.

56. Philippou E, Bovill-Taylor C, Rajkumar C, Vampa ML, Ntatsaki E, Brynes AE, Hickson M, Frost GS. Preliminary report: the effect of a 6-month dietary glycemic index manipulation in addition to healthy eating advice and weight loss on arterial compliance and 24-hour ambulatory blood pressure in men: a pilot study. Metabolism. 2009;58(12):1703-8. https://doi.org/10.101 6/j.metabol.2009.05.026.

57. Evans CEL, Greenwood DC, Threapleton DE, Gale CP, Cleghorn CL, Burley VJ. Glycemic index, glycemic load, and blood pressure: a systematic review and meta-analysis of randomized controlled trials. Am J Clin Nutr. 2017;105(5): 1176-90. https://doi.org/10.3945/ajcn.116.143685.

58. Lobos DR, Vicuña IA, Novik V, Vega CA. Effect of high and low glycemic index breakfast on postprandial metabolic parameters and satiety in subjects with type 2 diabetes mellitus under intensive insulin therapy: controlled clinical trial. Clin Nutr ESPEN. 2017;20:12-6. https://doi.org/10.101 6/j.clnesp.2017.04.082.

59. Sierra M, Garciía JJ, Fernaández N, Diez MJ, Calle AP, Álvarez JC, et al. Therapeutic effects of psyllium in type 2 diabetic patients. Eur J Clin Nutr. 2002;56(9):830-42. https://doi.org/10.1038/sj.ejcn.1601398.

60. Hanai H, Ikuma M, Sato Y, lida T, Hosoda Y, Matsushita I, Nogaki A, Yamada $M$, Kaneko E. Long-term effects of water-soluble corn bran hemicellulose on glucose tolerance in obese and non-obese patients: improved insulin sensitivity and glucose metabolism in obese subjects. Biosci Biotechnol Biochem. 1997;61(8):1358-61. https://doi.org/10.1271/bbb.61.1358.

61. Pereira MA, Jacobs DR, Pins JJ, Raatz SK, Gross MD, Slavin JL, et al. Effect of whole grains on insulin sensitivity in overweight hyperinsulinemic adults. Am J Clin Nutr. 2002;75(5):848-55. https://doi.org/10.1093/ajcn/75.5.848.

62. Anderson JW, Davidson MH, Blonde L, Brown WV, Howard WJ, Ginsberg H, Allgood LD, Weingand KW. Long-term cholesterol-lowering effects of psyllium as an adjunct to diet therapy in the treatment of hypercholesterolemia. Am J Clin Nutr. 2000;71(6):1433-8. https://doi.org/10.1 093/ajcn/71.6.1433.
63. Anderson JW, Hanna TJ. Impact of nondigestible carbohydrates on serum lipoproteins and risk for cardiovascular disease. J Nutr. 1999;129(7):1457S66S. https://doi.org/10.1093/jn/129.7.1457S.

64. Romero AL, Romero JE, Galaviz S, Fernandez ML. Cookies enriched with Psyllium or oat bran lower plasma LDL cholesterol in normal and hypercholesterolemic men from Northern Mexico. J Am Coll Nutr. 1998; 17(6):601-8. https://doi.org/10.1080/07315724.1998.10718809.

65. Chandalia M, Garg A, Lutjohann D, Von Bergmann K, Grundy SM, Brinkley LJ. Beneficial effects of high dietary fiber intake in patients with type 2 diabetes mellitus. N Engl J Med. 2000;342(19):1392-8. https://doi.org/10.1056/NEJM2 00005113421903.

66. Burke V, Hodgson JM, Beilin LJ, Giangiulioi N, Rogers P, Puddey IB. Dietary protein and soluble fiber reduce ambulatory blood pressure in treated hypertensives. Hypertension. 2001;38(4):821-6. https://doi.org/10.1161/hy1 001.092614

67. Jenkins DJA, Kendall CWC, Vuksan V, Vidgen E, Parker T, Faulkner D, Mehling CC, Garsetti M, Testolin G, Cunnane SC, Ryan MA, Corey PN. Soluble fiber intake at a dose approved by the US Food and Drug Administration for a claim of health benefits: serum lipid risk factors for cardiovascular disease assessed in a randomized controlled crossover trial. Am J Clin Nutr. 2002; 75(5):834-9. https://doi.org/10.1093/ajen/75.5.834.

68. He J, Streiffer RH, Muntner P, Krousel-Wood MA, Whelton PK. Effect of dietary fiber intake on blood pressure: a randomized, double-blind, placebocontrolled trial. J Hypertens. 2004;22(1):73-80. https://doi.org/10.1097/00004 872-200401000-00015.

69. Aleixandre A, Miquel M. Dietary fiber in the prevention and treatment of metabolic syndrome: a review. Crit Rev Food Sci Nutr. 2008;48(10):905-12. https://doi.org/10.1080/10408390701761886.

70. Chutkan R, Fahey G, Wright WL, Mcrorie J. Viscous versus nonviscous soluble fiber supplements: mechanisms and evidence for fiber-specific health benefits. J Am Acad Nurse Pract. 2012;24(8):476-87. https://doi.org/1 0.1111/j.1745-7599.2012.00758.x.

71. Streppel MT, Arends LR, Van't Veer P, Grobbee DE, Geleijnse JM. Dietary fiber and blood pressure: a meta-analysis of randomized placebo-controlled trials. Arch Intern Med. 2005;165(2):150-6. https://doi.org/10.1001/archinte.165.2.150.

72. Brown L, Rosner B, Willett WW, Sacks FM. Cholesterol-lowering effects of dietary fiber: a meta-analysis. Am J Clin Nutr. 1999;69(1):30-42. https://doi. org/10.1093/ajcn/69.1.30

73. Cho SS, Qi L, Fahey GC, Klurfeld DM. Consumption of cereal fiber, mixtures of whole grains and bran, and whole grains and risk reduction in type 2 diabetes, obesity, and cardiovascular disease. Am J Clin Nutr. 2013;98(2): 594-619. https://doi.org/10.3945/ajcn.113.067629.

74. Jonnalagadda SS, Harnack L, Hai Liu R, McKeown N, Seal C, Liu S, Fahey GC. Putting the whole grain puzzle together: health benefits associated with whole grains - summary of American Society for Nutrition 2010 satellite symposium. J Nutr. 2011;141(5):1011S-22S. https://doi.org/10.3945/jn.110.132944.

75. Cho SS, Qi L, Fahey GCJ, Klurfield DM. Consumption of cereal fiber, mixtures of whole grains and bran, and whole g...: Discovery Service for Endeavour College of Natural Health Library. Am J Clin Nutr. 2013;98(594):26. https:// doi.org/10.3945/ajen.113.067629.594.

76. Wanders AJ, van den Borne JJGC, de Graaf C, Hulshof T, Jonathan MC, Kristensen M, Mars M, Schols HA, Feskens EJ. Effects of dietary fibre on subjective appetite, energy intake and body weight: a systematic review of randomized controlled trials. Obes Rev. 2011;12(9):724-39. https://doi.org/1 0.1111/j.1467-789X.2011.00895.X.

77. Harrington S. The role of sugar-sweetened beverage consumption in adolescent obesity: a review of the literature. J Sch Nurs. 2008;24(1):3-12. https://doi.org/10.1177/10598405080240010201.

\section{Publisher's Note}

Springer Nature remains neutral with regard to jurisdictional claims in published maps and institutional affiliations. 